\title{
Expertise and Explicitation in English Translations of the Holy Quran
}

\author{
FATEMEH RAOUFKAZEMI \\ Department of Translation Studies, Tabriz Branch, \\ Islamic Azad University, Tabriz, Iran \\ f.raoufkazemi@gmail.com \\ MAJID KHORSAND \\ Department of Translation Studies, Tabriz Branch, \\ Islamic Azad University, Tabriz, Iran \\ MOUSSA POURYA ASL \\ School of Humanities, \\ Universiti Sains Malaysia, Malaysia \\ AMIN AMIRDABBAGHIAN \\ Curatorial Affairs Department, Islamic Arts Museum Malaysia, \\ Kuala Lumpur, Malaysia
}

\begin{abstract}
With universals of translation budding into an interesting field in translation studies, discussing the nature of translation universals and explicitation as one of the universals of translation emerges as one important strand worthy exploring. In this paper, first of all, the notion of explicitation in translation is introduced, followed by the probable relations between expertise and explicitation discussed in two Arabic-English translations of the Holy Quran. First, a comparison was made between the original text and the translations in terms of explicitation regarding cohesion in context. Second, the translations were compared by studying cohesive markers. In the third step, the study investigated the relationship among features of cohesion, as verified by Halliday and Hassan's seminal work in this realm, with all instances of explicitation identified on this basis. The fourth stage of the study saw a comparison drawn between the frequencies of explicitation in the translations. The findings pointed to the application of explicitation, somehow affecting the behavior of cohesive markers. Finally, the results of the analysis supported the need for the reasons behind the rate of the relationship between expertise and explicitation in the Arabic-English translations of the Quran. Interestingly, the findings turned out to be in contrast with the hypothesis indicating that the translated texts converted by experienced translators would be more explicit than their original parallel versions. Further, experienced or inexperienced translators transferred most of the ellipsis and substitutions used in the source text in their original form. No clear relationship between the level of expertise of translators and explicitation in translation was discovered. Such detailed investigations of the instances of explicitation in corpora would be attempts to categorize, compare and contrast patterns of occurrence, and provide possible starting points for further similar research.
\end{abstract}

Keywords: Translation; Explicitation; Expertise; Cohesion; Cohesive Markers

\section{INTRODUCTION}

Translation studies, as an inherently interdisciplinary enterprise, is a boldly emerging academic discipline concentrating on the organized study of translation in all its myriad guises and forces (Munday, 2016). One of the fundamental aspects of the discipline is exploring the nature of translation universals and their implications for the translator's performance. There is an inseparable connection between the history of translation universals (Malmkjær, 2017) in translation studies and explicitation. Explicitation is an important translation universal that raises many questions to do with a certain measure of dubiety when looking upon the integrity of interpretation. As the practice of generating the original data more specific (Tang \& $\mathrm{Li}$, 2017), according to Klaudy (1998), explicitation is a process in which the transformation of implicit data in the original language is done into explicit one in the target language. One strong 
ripple of theory making in Translation Studies was "explicitation hypothesis", the idea that original content is less explicit and more implicit than its translations (Blum-Kulka, 1986, pp. 19-21). However, there is still much-unchartered territory that exploring the explicitation hypothesis in practice would be laid out.

As a communicative act, translating is influenced by different elements, such as the translator's professional knowledge and personal experience. This suggests that the translator's competence works hand in hand with his past involvement and background in translation towards shaping the ultimate product of the text (Dimitrova, 2005, p. 1). As Dimitrova (2005) argues, there is a direct relationship between the translator's amount of experience and the frequency of explicitation in translated texts. Nevertheless, different studies point to conflicting results.

Going with a mainstay in the hypothesis of Kulka's concerning explicitation (1986), "translations are generally more explicit than texts originally written in one language". Although many kinds of research have been undertaken to substantiate this hypothesis, few studies have sought to see to what extent the translator's experience is significant in the translation process. Thus, the issue of the possible relationship between the frequency of explicitation in the translated products and the experience of the translator is a worthwhile and research-worthy effort.

Nevertheless, scholars have not reached consensus on the role possibly played by expertise in the frequency with which explicitation is seen to occur in the translation product. This study looks at the role of expertise in translation between Arabic and English. It also provides a set of findings that will hopefully be useful in translator training programs. The Holy Quran is the religious text chosen for this study. This holy text is the main written source of Islam (Mohaghegh and Pirnajmuddin, 2013, p. 51) and includes some linguistic items with multiple meanings (Abdul-Qader Khaleel et al, 2019, p. 130) which need to be carefully scrutinized. The most important features of the Quran that made it an appropriate candidate for this investigation are as follows (Khansary, 2009):

(a) the miraculous nature of the text and the inability of a man to bring forth the like of it

(b) The uniqueness of form, incomparable with any kinds of literary forms

(c) The divinity of origin, the speech of the Creator in word and meaning, revealed to the Prophet Mohammad.

Translation of the Quran is considered a sensitive and vital issue among Muslims in order to spread Islam; therefore, it makes the job difficult for translators in terms of accuracy and translatability (Amirdabbaghian, 2017). Upon its completion, this study hopefully introduced some conducts where the expertise of the translator is manifested in explicitation. Explicitation in The Holy Quran and Halliday's idea of cohesion in English were of foremost concern to the researchers in this study, which is an attempt to show which cohesive markers are more explicit and which ones less explicit in the translated texts, and, by extension, to see whether the translator's expertise potentially affects explicitation or not. Two English translations of The Holy Quran were chosen, one by a professional (TT1), and the other by a novice translator (TT2), with the frequencies of explicitation of each cohesive marker type analyzed in turn.

The two translations of the Quran, the names of the translators, and the years of translation publication are as follows:

(1) A Simple Translation of The Holy Quran (with notes on Topics of Science) (1993) by Dr. Mir Aneesuddin published by the Islamic Academy of Sciences.

(2) The Nobel Qur'an (1992); by Dr. Thomas Ballantyne Irving / T.B. Irving (Al-Hajj Ta'lim Ali Abu Nasr). The Arabic text with English translation and commentary by Dr. Irving is published by Amana Books, Brattleboro, Vermont. 
This paper attempts to explore the correlation between explicitation and expertise (translation competence) mostly based on contrastive analyses of the translation products and their source text; few studies have undertaken to shed light on how expertise and explicitation are connected and related together in translation (Tang \& Li, 2017). In other words, one of the reasons behind the study, along with its objectives, is to discover why translations are more or less explicit or implicit than the original text. Another significant issue is that the relation between the rate of explicating or implicating the content of the original in the product of translation to what extent depends upon the level of expertise of the translator. Further, the purpose of this study is, in particular, the examination of ellipsis, substitutions, and conjunctions in English translations of the Quran in distinct comparison with the original version with a central focus on the professionalism of the translators.

\section{ON THE NOTION OF EXPLICITATION}

Although proposing explicitation as a vital issue in Translation Studies goes back to the 1950s, the interest in translation universals has only arisen over the last two decades. Vinay and Darbelnet (1995) were the first to introduce this concept in 1958. According to this view, explicitation is "the process of introducing information into the target language which is present only implicitly in the source language, but which can be derived from the context or the situation" (p. 170).

Nida further developed explicitation in 1964. At the forefront of studying explicitation was Blum-Kulka (1986) who articulated the commonly named "explicitation hypothesis", which "[...] postulates observed cohesive explicitness from SL to TL regardless of the increase traceable to differences between the two linguistic and textual systems involved" (Blum-Kulka, 1986, p.19). She also made a point of the fact that the translated texts are further explicit than the original texts, disregarding the language-specific explicitness. Later, Baker defined explicitation universal as the inclination toward "spelling things out rather than leaving them implicit" (Baker, 1996, p.175) Candace Séguinot insisted on "the need to reserve the concept of explicitation for additions in a translated text which cannot be explained by structural, stylistic or rhetorical differences between the two languages" (Séguinot, 1988, p. 108).

Pym (2005) described two categories of explicitation: obligatory and voluntary. Vander (1985) suggested a series of explicitation divisions involving: abridged texts which are extended, modifiers that are added, qualifiers and conjunctions which are utilized aiming at superb clarification, further data, and details which are accumulated, etc.

Even so, to reiterate, Kulka was the first scholar to make a systematic study of explicitation under the rubric of an "explicitation hypothesis" in 1986. According to Kulka (1986), accomplished by the translator, the practice of interpretation might turn out to be further dismissed than the original text. This dismissal is manifested by an increase in the amount of explicitness that is cohesive in the translation and may be captured by the term "explicitation hypothesis". Since Vinay and Darbelnet (1958), various studies with different approaches have been carried out on explicitation and its nature.

Klaudy and Károly (2005, p.15) believed that variable circumstances contribute to explicitation being, at the end of the day, either an unconscious operation or a thoughtful strategy, or a combination of both. Some researchers advocate the idea that explicitation is a translation universal; in contrast, others persist in their view that it is a technique-driven mostly by a conscious path of translation.

As mentioned above, scholars are yet to reach a consensus on the reasons and motivations behind explicitation. The likes of Blum-Kulka (1986) are of the opinion that explicitation is fuelled by processes integral to the act of translating, while others are of the idea that explicitation is due to restrictions in interpretation typical of the language systems 
involved, as well as the differing stylistic strategies, text building strategies, and cultural differences between the two language systems (Klaudy, 1993).

\section{TYPES OF EXPLICITATION}

Various positions have been declared concerning the precise definitions and types of explicitation. Frankenberg-Garcia (2004) claims that explicitation is of two types: obligatory and optional. When the addition of data is required in the ST content by virtue of requirements of the target language grammar, we have a case of obligatory explicitation on our hands. When the translator distances himself from the ST, where he renders the translation to be readily comprehensible, it is called optional explicitation. Other scholars like Pym (2005) and Klaudy \& Karoly (2005) made a distinction between symmetric and asymmetric explicitation. Explicitation was identified and categorized into four classes by Klaudy (1998): pragmatic or sensible, obligatory or mandatory, optional or elective, and translation-inherent.

Baker (1993) suggests four features of translation that could be universals; explicitation, leveling out, normalization, and simplification. Later Baker and Olohan (2008) discussed the recurrence of the optional "that" in conjunction with the two verbs 'say' and 'tell' in the translated contents into English and texts initially written in English. They concluded that in comparison with authors of original English texts, translators of these texts use the explicit "that" redundantly.

After Halliday, House (2004, p. 203) came to form a distinction between three types of explicitation, which was a question of whether it relates to ideational, interpersonal, or textual functional components. In each of these types, explicitness can assume three different forms: a) Elaboration b) Enhancement, and c) Extension. By elaboration, we mean the explanation of the clause or part of it by the application of other terms and expressions, providing examples, comments and details. Enhancement indicates embellishing or qualifying the clause by the conditional, temporal, or local causal elements. Moreover, extension refers to adding novel components, providing exceptions, or proposing a substitute.

There are two types of explicitation, as Blum-Kulka (1986) overtly admits: First, the explicitness of different sorts between the original and the translation version and, second, the explicitness of converted form, i.e., the product of explicitation in the translation process. This implies that since some shifts in the translation are based on the alterations in the system of linguistic and stylistic sort between the two languages, they are not realized as cases of explicitation. In fact, the real examples of explicitation, as Blum-Kulka states, are the shifts triggered by the TL structure and conventions of communicative type.

\section{EXPERTISE AND EXPLICITATION}

As an act of communication, translating is affected by different factors. For instance, sociocultural factors determine what translated texts ought to be produced in a particular society. The final shape of the text is influenced by editors, publishers, and translators as well. In this manner, the translator's professional knowledge and personal experience play an immutable roles role in translation practice. Strictly speaking, how the outcome of the text is shaped hinges upon the translator's aptitude and his prior background.

The correspondence between explicitation and the rate of background practice in translation is a mainstay of this study. That said, some researchers assume quite the opposite; they regard explicitation as being distinctive of translations generated by non-experienced/ under-experienced translators. According to Blum-Kulka (1986), however, both professional and non-professional translators produce explicitation. In Laviosa Braithwaite's (1998) opinion, translations of non-professional translators tend to be more explicit. Assuming the great variety of studies on expertise and explicitation and their differing results, this study is 
another approach to the possible relations between expertise and explicitation, in this case, within Arabic-English translation.

\section{METHOD}

This study chose two translations of the Holy Quran, one by Irving (1992) and the other by Mir Aneesuddin (1992), who was born in India. This work was his first translation, which leads to the natural assumption for this work of his to cast him as an inexperienced translator. Born in Canada, Irving, on the other hand, wrote and translated many books and is known by his reception and work standing as an experienced professional translator. Having compared the original with translated texts besides drawing a comparison between the translations, all cases of explicitation, going by Halliday's (1976) categorization of cohesion in English, were identified and categorized. Accordingly, the behavior of ellipsis, conjunctions, and substitutions in the Quran was first studied. Comparisons were then drawn between the frequencies of explicitations inexperienced and non-experienced translators, followed by the relevant analyses.

In the present study, adopting an interpretive and qualitative approach is corpus-based, comparative, and descriptive work. The profile variable in this research is comprised of Halliday's (1976) categories of cohesion in English.

The researcher picked ten chapters of the Quran, namely Al-Baqarah, Al Imran, AlAn'am, An-Nisa, Hud, Yusuf, An-Nahl, Maryam, Yaseen, Al-Munafiqoon, in ST and TT, and analyzed them. The errors were identified, analyzed, classified and the frequency of their occurrences was computed by finding the total numbers of explicitated and transferred ellipsis, conjunctions, and substitutions to see whether a statistically significant difference emerges.

The explicitation hypothesis (Blum-Kulka, 1986) was the theoretical framework of this study. As she argues, non-translated target language texts have an incline to be less explicit than all translated texts of a comparable type. Halliday and Hasan's (1976) categorization of cohesive markers in English was constitute the analytic tools of this research in finding the cases of explicitation. Halliday and Hasan assert that "there are five cohesive markers in English: conjunctions, ellipsis, lexical, reference, and substitution cohesion." To explore the cohesive ties within the original texts, three types of cohesive markers, namely, ellipsis, conjunction, and substitution, were taken into account.

In two translations of the Holy Quran, explicitation cases were observed here, one by Dr. Irving (1992), the experienced translator, and the other by Mir Aneesuddin (1992), the nonexperienced one. In analyzing the data, to identify and classify instances of explicitation in the translations, the researchers acted in accordance with Blum-Kulka's (1986) explicitation hypothesis, in conjunction with the categorization of cohesive markers in English based on Halliday and Hasan's (1976).

The two translations being quite contemporaneous means that the two could not have been influenced by each other. This involves two facets. First, the longer the interval between the translations, the more possible that sociocultural factors, other than the translators' experience, might influence the translations, i.e., the differences may then not be due to the translators' experience but to a series of sociocultural factors. Second, if the translations were not undertaken almost contemporaneously, the translator was affected by the other's (already completed) translation. TT1 points to Irving's work and TT2 to Mir Aneesuddin's. 


\section{ELLIPSIS}

As a cohesive device, ellipsis refers to the omission of words, already specifically mentioned, when the repetition of a phrase is needed; it is a zero-replacement relation, that is, the omitted item is replaced by nothing.

Ellipsis is a truly ubiquitous textual device in English. It manifests itself par excellence both below the clause and above it, stretching beyond the clause and creating cohesive bonds over a stretch throughout one clause complex that can be composed of many clauses inside it. In this sense, ellipsis enters into many inter-clausal and intra-clausal relations.

Many of the non-finite clauses, what he calls non-finite adverbials or adverbials, in short, are elliptical (Hadidi, 2016). In his paper, he outlines, with examples from the corpus, how this is the case, demonstrating that, instructively and instructionally speaking, looking at these nonfinite elements in this elliptical light will have remarkable promise in paving the path for learning them, within a simplified model most accessible to advanced learners of English who wish to keep their proficiency alive by authentic means. This, we believe, could well extend to the remit of aspiring translators as well. Hadidi comments that one of the important textual functions carried off by ellipsis, with, for instance, the process lying at the heart of some nonfinite adverbial phrases that are originally adverbial clauses, is rank-shifting; 'one can assume that the type of unpacking undertaken here whose aim was simplification and instruction is inspired and made inherently possible by the availability of the process of rankshifting itself' (p. 29). Rank-shifting allows something that is originally a clausal element (with participants and a process type) to be expressed in the form of a phrase (one rank lower) (Halliday and Matthiessen, 2004; Thompson, 2004).

In Hadidi's account, ellipsis makes for cases in the interpretation of text where both of a pair of interpretations apply, even without pragmatic recourse to syntagmatic contextual parameters. He adds that this might, of course, be what literature-text (or similar text types) is organized around: necessary indeterminacy and ambiguity as an integral part of semiosis. This principle of literary discourse manifests itself noticeably in cases where both senses can apply without one amenable to cancelation. Looked at from a systemic, Hallidayan perspective, such semiotic phenomena could be cases of (grammatical) metaphor, where stratal tension occurs between the lexicogrammar and the semantics, semantic compounding, and some transference of meaning (Ravelli, 1999), among several other features. In this sense, again, ellipsis seems to have the potential to trigger many other far-reaching textual forces, possessing the capacity to set them in motion.

Another comment Hadidi makes about his elliptical adverbials and, by extension, the rippling synergistic strength of ellipsis in a body of the text is that elliptical patterns could also be viewed as figures of speech. Seeing as ellipsis is so ubiquitous in English, he cites Kienpointner (2011), who states that Figures of Speech are not solely embellished or appealing gadgets; they are, in fact, devices that provide our mentality and culture-specific perception of nature with structure and pattern. Furthermore, figures of speech that are the output of discourse approaches are utilized to generate texts for the communicative aims by selecting items from linguistic patterns of diverse stages (semantics, syntax, morphology, phonetics/phonology) (in the realm of spoken and written genres).

To add strength to the notion that ellipsis is so important as to be similar to and classifiable as a figure of speech in its own right, or many FSPs in different guises and types, Hadidi continues to use Kienpointner's manner of putting forward a type argument which is pragmatic in contradiction of typologies which are structurally inclined by asserting that figures of speech ought to be viewed as linguistic component possessing specific communicative purposes. He argues that these functions could well accrue to the elliptical adverbials he discusses. They could, he argues, be used by prose fiction writers for stimulating interest, for 
aesthetic and cognitive pleasure (he states that one path to this is simultaneous readings and interpretations in literature), modifying and adjusting the cognitive perspective (theme/rheme and old/new information structure change when adverbials are elliptical, hence cognitive adjustment of the reader), and so on.

Yet another comment Hadidi makes about his elliptical patters is their evidencing a type of parallelism in prose literature and similar/related genres, an overarching term of linguistic stylistics that refers to repetition or parallel use of similar or similar-sounding words, sounds, or constructions. Although he does not treat them in his study, he points out that these patterns of the adverbial are, indeed, used in parallel fashion in English fiction text very markedly. What he means by this is that each of the different patterns of the elliptical adverbial he outlines occurs not only by itself, next to the main clause (i.e., the patterns outlined by him are all of this type: one main clause - one elliptical adverbial), but it is seen to also occur parallel with other elliptical adverbial types in the sentence and on the right or left of the main clause, which means that ellipsis is an important part of cohesion not just below the clause but above and beyond it as well. In his discussion of cohesion, Gutwinski (1976) argues, in essence, that grammatical parallelism is part of cohesion. He maintains that in all models of cohesion, the ellipsis (i.e., resources for omitting a clause or part of a clause) constitutes a chief component. Hadidi and Gutwinski both make the argument for the inclusion of all connectors into cohesion, whether the clauses within or between sentences are linked or not. In this sense, ellipsis and conjunction, as were mentioned, are in stronger bonds than otherwise thought.

Having now established the importance of ellipsis in English and, by natural extension, in any act of translation to and from English, it should be noted that, according to Halliday, the decided majority of instances of ellipsis that occur in texts are classified in the anaphoric category. Being curbed to adjacent passages, substitution and ellipsis are integral facets of verbal texts. They do, however, exist in written texts as well, serving as textual devices that prevent presupposed references from being unnecessarily repeated. In the light of this anaphoric referencing function, ellipsis contributes to the building of a sense of cohesion all through the text. Furthermore, the outcome that can be observed is ample cohesiveness (Halliday and Matthiessen, 2004; Crane, 2006).

Here are some examples of ellipsis in the translations:

$$
\begin{aligned}
& \text { SAMPLE ONE OF ELLIPSIS. ST: 16:30 }
\end{aligned}
$$

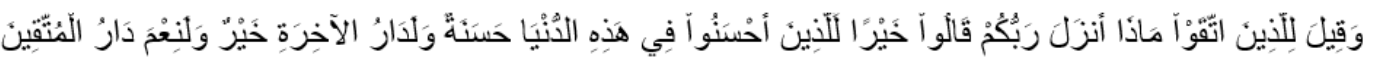

TT1: Those who have done their duty will be told: "What has your Lord sent down?" They will say: "(The very) Best!" Those who have acted kind in this world will have a fine thing, while their Home in the Hereafter will be even better.

TT2: And (when) it is said to those who guard (against evil), "What has your Fosterer sent down?" They say, "Good. For those who do good in this world is good, and the home of the hereafter will be better, and the home of those who guard (against evil) is excellent.

Discussion. The assumed elliptic word is "أنزل " [he has revealed] after the verb [say] (Siyouti, 2003, vol.3). Both translators experienced, and novice turned out to have rendered the elliptical form as it is. In other words, no explicitation was made on the elliptical part by any of the translators. 


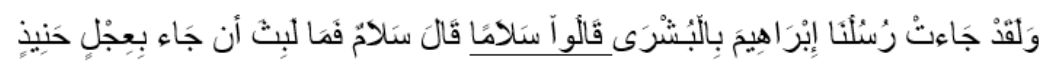

TT1: Our messengers came to Abraham with good news. They said: "Peace!"; he said: 'Peace!", and immediately set about bringing in a roast calf. When he saw their hands did not reach out towards it, he felt uneasy with them and started to be afraid of them.

TT2: And Our messengers came to Ibrahim with good news. They said, "Peace," he said, "Peace," then he did not delay in bringing a roasted calf.

Discussion. The word assumed to have undergone ellipsis is "نسلم" [We greet] after the verb "said" (Siyouti, 2003, vol.3, p. 234). Again, the ellipsis here has remained intact in the process of translation without making any changes. Neither the inexperienced nor the proficient translators explicitated the elliptical forms.

$$
\begin{aligned}
& \text { SAMPLE THREE OF ELLIPSIS. ST: 16:115 }
\end{aligned}
$$

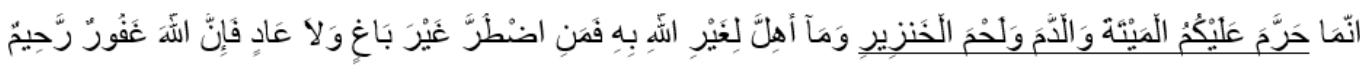

TT1: He has only forbidden you carrion, blood, and pork, as well as anything that has been consecrated to something besides God. Yet anyone who is obliged to do so without desiring it nor going to excess (will find) God is Forgiving, Merciful.

TT2: He has forbidden for you only: the dead and blood and flesh of swine and that over which (a name) other than that of Allah has been invoked, but one who is driven to necessity (being helplessly forced to eat) neither desiring it nor revolting, then Allah is certainly Protectively Forgiving, Merciful.

Discussion. The word that can be assumed elliptical (omitted) is "تناول [eating] in "تناول

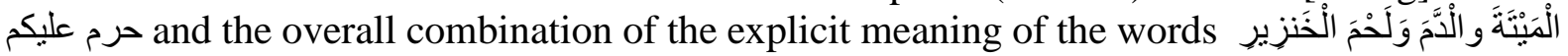
[carrion, blood, and pork and the dead and blood and flesh of swine] point to the ellipted word تناول [eating] (Siyouti, 2003, vol.3). In this case, again, both Irving and Aneesuddin rendered it in English without any explicitation.

SAMPLE FOUR OF ELLIPSIS. ST: 12:82

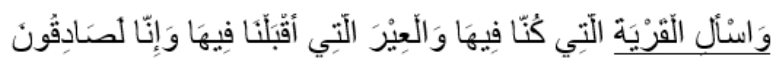

TT1: Ask the town [folk] where we have been and the caravan which we came back in; we are telling the truth!

TT2: And inquire in the city in which we were, and (also from) the caravan with which we travelled and we are certainly truthful.

Discussion. In some cases, only shrew intellect and sheer linguistic acumen could come to the aid of comprehension using furnishing and putting an instance of ellipsis back into the text, as discursive coherence and pragmatic sense-making have proved to be impermissible by the reader's cognitive efforts unless there is an allowance made by the cognitively wellequipped reader/analyst for an assumed elliptic part. The reading of such a reader would reconstruct the supposed deleted word " هل [folk] (Siyouti, 2003, vol.3). In this example, Irving translated the sentence by an explicit move to bring the unuttered words to the surface while his novice counterpart did not make the same explicitation move. 


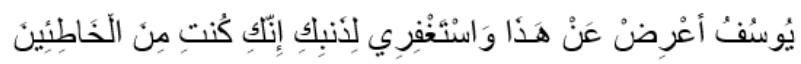

TT1: Joseph, avoid this. [My wife], ask forgiveness for your sin. You're someone who has slipped up.

TT2: Yusuf: turn away from this and (O my wife:) ask protective forgiveness for your sin, you are certainly of those women who are at fault.

Discussion. Many of the reasons involving explicitation of ellipsis serve the purpose of compacting and condensing the discourse (Farahani \& Hadidi, 2008) and the principle of linguistic economy, amounting to coming up with a way to decrease somehow the size of language and number of words used. When the message necessitates a certain verbosity or plentifulness in linguistic means, speakers, out of necessity, have recourse to deletion, like the ellipsis of the vocative particle in verse 29 of Chapter Yusuf " يُوسُفْ أَعْرِنْ عَنْ هَذَا ( Az Zarkashi, 2001, vol.3). Neither of the translators made the elliptical forms explicit.

\section{CONJUNCTIONS}

According to Halliday, conjunction is, in fact, "a clause or clause complex, or some long stretch of text, (which) may be related to what follows it by one or other of a specific set of semantic relations" (Halliday, 1976, p. 310). While ellipsis and substitution, because of their anaphoric references, produce cohesion in text, conjunction, in contrast, does not necessarily serve to form a semantic bond within just one part of the text; it serves to spread semantic connectedness and bonding across a larger stretch of text.

According to Baker (1992, p. 190), the use of conjunction in Arabic and English is different. While Arabic has a preference for grouping information into large chunks and using a fairly limited number of conjunctions, each of which is multi-functional and whose meaning varies based on context, English, on the other hand, prefers small chunks in which the connections among parts of these chunks are explicitly marked by using different conjunctions. This indicates that-clauses, sentences, and paragraphs have semantic relations in between. Accordingly, a reader has to consider which meaning is intended in line with the given context and cues from these same conjunctions.

Here are examples of conjunctions in the translations:

SAMPLE ONE OF CONJUNCTIONS. ST: 19:49

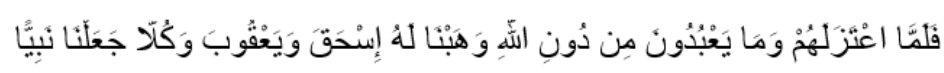

TT1: When he moved away from them and what they worshipped instead of God, We bestowed Isaac and Jacob on him. Each We made a prophet.

TT2: So when he withdrew from them and that which they worshipped besides Allah, We granted to him Ishaq and Yaqub and We made each one of them a prophet.

Discussion. In this example, the novice translator made the conjunction used in the source text explicit in the translation. Leaving the source text conjunction explicit in the translation denotes faithfulness to the original version. In fact, even a minor violation of the source text conjunction in the translation leads to the semantic distortion in the readers' mind since any conjunctions carry specific textual and contextual connotations. 


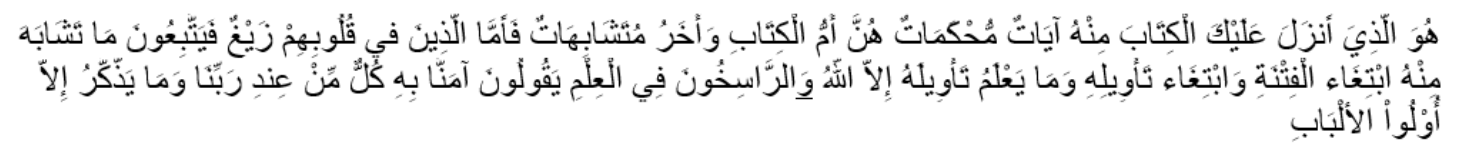

TT1: Those whose hearts are prone to falter follow whatever is allegorical in it, seeking to create dissension by giving [their own] interpretation of it. Yet only God knows its interpretation; those who are versed in knowledge say: We believe in it; it all comes from our Lord! However only prudent persons bear it in mind.

TT2: He it is Who has sent down the book to you, in it are statements which are decisive, they are the basis of the book and others are allegorical. So those in whose hearts is (a desire for) deviation from the right, they follow that which is allegorical in it, seeking to mislead and seeking to interpret it, and no one knows its interpretation except Allah; and those sound in knowledge say, We believe in it, all is from our Fosterer, and no one minds except those who have understanding.

Discussion. Abdul-Raof (p. 32) asserts that a violation in the structure of this verse must occur in the transition of the leading chunk following an altered sentence. The term 'and' which is conjunction appeared after God used by the translator to relay Arabic into English quickly leads to vagueness incomprehension. The conception of the reader perceived by this conjunction designates that those who are profoundly possessed of true knowledge are partners to God in the knowledge of hidden truths that only God is entitled to. This stems from the fact that 'and' in Arabic abound with functions which, in this case, serves the role of emphasis. The emphasis developing in verse accentuates that intellectuals place unbounded and complete faith in God's knowledge. However, this is not attended to here, which triggers changes in meaning, to the effect that God and those possessed of knowledge are subjects of the sentence and are alike. This has a disastrous impact on the reader's perception of the true message and semantics of the Quranic. Interestingly, in this sample, only the novice translator made this part explicit.

SAMPLE THREE OF CONJUNCTIONS. ST: 36:27

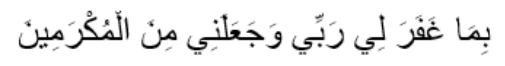

TT1: He said: "If my people only knew how my Lord has forgiven me and placed me among the honoured ones!"

TT2: (the reason) because of which my Fosterer protectively forgave me and placed me among the honoured ones.

Discussion. In this example, both translators left this conjunction (و) [and] explicit in the process of translation as the source text. This conjunction designates 'in line with' or 'as well as'. Since 'forgiveness' possesses the connotation of 'granting' proceeding the act of forgiving; thus, the clause after the conjunction (و) [and] refers to forgiveness being in line with honoring.

SAMPLE FOUR OF CONJUNCTIONS. ST: 6:42

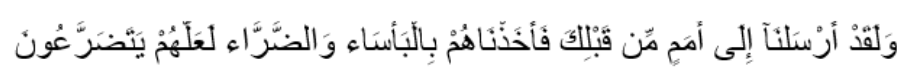

TT1: We sent [word] to nations before you and seized them with suffering and hardship so that they might act submissively.

TT2: And We had sent (messengers) to communities before you, then We afflicted them with distress and harm that they might humble themselves. 
Discussion. In this sample, interestingly, the novice translator made explicit the first conjunction in verse, but the experienced one did not. The second of conjunction, both translators rendered into English, albeit slightly differently but to the same effect in English, using 'and' or 'then' to show the sequence of events, as intended in the source text.

SAMPLE FIVE OF CONJUNCTIONS. ST: 2:179

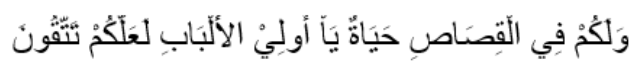

TT1: Anyone who exceeds the limit after that shall have painful torment. You will find [security for] life in [such] compensation, O prudent persons, that you may do your duty!

TT2: And in (the law of) retaliation there is life for you, $\mathrm{O}$ you who understand, that you may restrain (from killing or harming uninvolved innocent people).

Discussion. Again, in this example, the novice translator left the conjunction in the source text (و) explicit in the translation, but the experienced translator ignored it. Removing the conjunction in this verse signifies no relationship or eradication of any relation between the present and the former verse.

\section{SUBSTITUTIONS}

As a cohesive device, substitution refers to one item being replaced by another; it is a lexical relation rather than a semantic one. When a substitution occurs in the text, it follows that the substituted item, as the presupposed item, retains the same structural function. Here are the examples of substitution in the translations:

SAMPLE ONE OF SUBSTITUTIONS. ST: 4:43

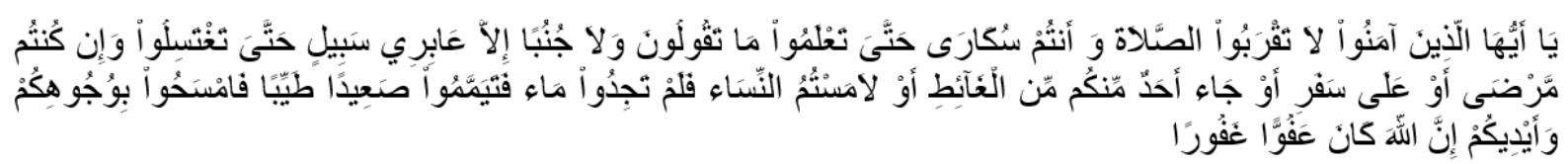

TT1: You who believe, do not attempt to pray while you are drunk, until you know what you are saying; nor after a seminal emission - except when traveling along some road until you take a full bath. If you are ill or on a journey, or one of you has come from the toilet, or has had contact with any women, and you do not find any water, then pick up some wholesome soil and wipe our faces and your hands with it. God is Pardoning, Forgiving.

TT2: O you who believe! do not go near worship (salat) when you are intoxicated (not conscious) until you know what you say, nor when you have not taken a bath after sexual intercourse (or passing out of semen during sleep etc.) until you have bathed, except when you are traveling on a road, and if you are sick or on a journey or one of you comes from the toilet or you have touched women, then (under the above circumstances if) you do not find water then take clean dust and wipe your faces and your hands, Allah is certainly Pardoning, Protectively Forgiving.

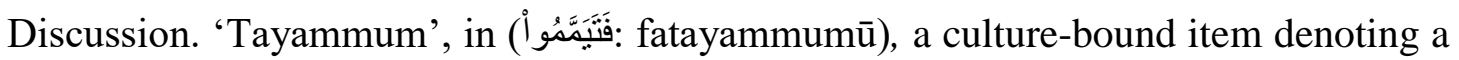
religious ritual in the absence of ablutions water in preparation for prayer in Islam, lacks equivalence in English. Therefore, translators should substitute it with explicit equivalents or glosses/descriptions. In this sample, both translators made this elliptical item explicit in the process of translation. 


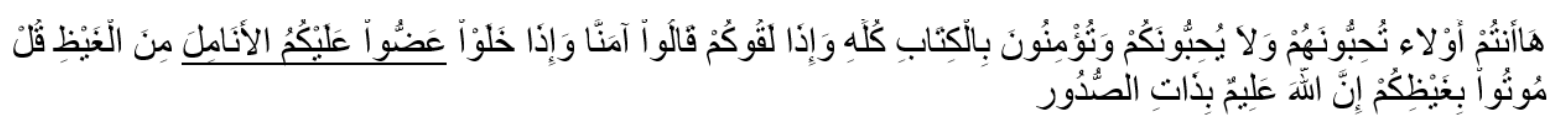

TT1: Here you are, loving such people while they do not love you! You believe in the whole Book. Yet whenever they meet you, they say: "We believe;" while when they go off by themselves, they gnaw away at their fingertips in rage over you. SAY: "Die in your rage!" God is Aware of what is on your minds.

TT2: Ah! You are those who love them but they do not love you, and you are those who believe in the whole of the book. And when they meet you, they say, "We believe," but when they are alone, they bite their fingertips because of (their) anger on you. Say, "Die in your anger." Allah is certainly the Knower of that which is in the bosoms (hearts).

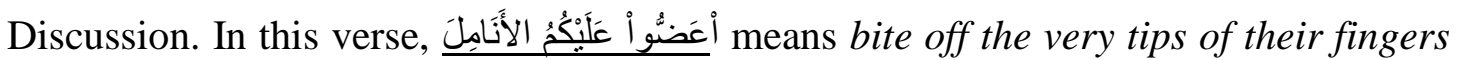
(Abdel Haleem, 2005, p. 43). As can be seen, both translators made explicitly and substituted the right cultural element in verse. Cultural references are, at times, too specific. The conventional target culture notions may be entirely opposed by the implication of one expression in a source culture. Cultural items are on occasion, explained by translators through their meaning in the ST). Merely a literal translation, on the other hand, is given by other translators, which may result in some vagueness. The expression (عضو ا.....الغيظ) embraces two elements; rage and regret, which are vague in the above translation. Though, Abdul-Raof (2004, p. 105) advocates in this example for a cultural substitution with which the addressees are acquainted. Since immense alterations may happen through substitutions, any exchange for cultural references is not always preferable and recommended even if it is culture friendly towards the readers.

SAMPLE THREE OF SUBSTITUTIONS. ST: 63:4

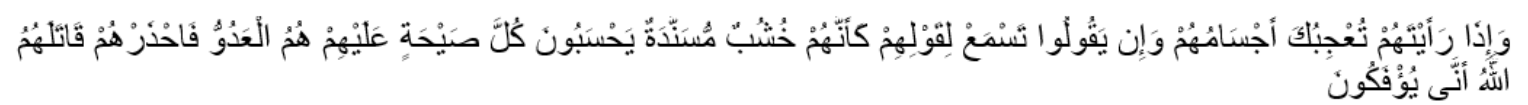

TT1: Whenever you see them, their physical appearance may attract you, while if they speak, you will listen to what they say as if they were just sticks of kindling all stacked up. They reckon every shout is [directed] against them. They are the [real] enemy, so beware of them! May God assail them! How they shrug things off!

TT2: And when you see them, their personalities please you and if they speak, you listen to their speech. They are like beams of wood covered with (attractive) garments, they think that every loud cry is against them, they are the enemies, so beware of them. May Allah kill them, how they are turned away (from the truth)!

Discussion. In this example, '́xuŝbun musannada (خُشَبُّ مُسَنَّةُة) refers to hypocrites. The ancient Arabs had a ritual involving planks of wood placed against the back wall of their houses when they were not used (Abdul-Raof, 2004, p. 105), which meant that, in their culture, such planks of wood were, for the most part, otherwise useless. This expression is addressed to people who are worthless at their core, serving no real purpose in the community. However, the translation fails to render either the sense or the intended meaning of kuŝsubun musannada. The translators, as one possible solution, could have substituted the source culturally laden practice and ritual with another one in the target text alongside beams of wood covered with (attractive) garments and sticks of kindling all stacked up. Although both translators made this elliptical item explicit in the process of translation, none of them captures the true intended meaning of a worthless person. 


\section{DATA ANALYSIS}

In this study, the data were gathered in two ways. In the first step, there was a comparison drawn between translations and the original text; in the second, there was another comparison between the translated texts. Later on, building on Blum-Kulka's (1986) explicitation hypothesis and Halliday and Hasan's (1976) categorization of cohesive markers in English, all cases of explicitation were identified in the original texts and their translations. Then, after numbering the overall cases of explicitation in the translated texts, they were compared with the original.

The analysis of the findings of this section is presented in tables 1,2 , and 3 . The information that appeared in the tables elaborate the quantity of the relevant cases as well as the translators' tendency towards ellipsis, conjunctions, and substitutions.

TABLE 1. Total Quantity of Ellipsis, Explicitated and Transferred Ellipsis

\begin{tabular}{ccccc}
\hline Text & Studied Words & $\begin{array}{c}\text { Quantity Of Ellipsis } \\
\text { Found }\end{array}$ & $\begin{array}{c}\text { Quantity Of } \\
\text { Explicitated Ellipsis } \\
\text { By Both Translators }\end{array}$ & $\begin{array}{c}\text { Quantity Of } \\
\text { Transferred Ellipsis } \\
\text { By Both Translators }\end{array}$ \\
\hline The Glorious Quran & 10660 & 36 & 4 & 32 \\
\hline
\end{tabular}

Table 1 demonstrates that 10660 words were under investigation in this study, where 36 cases of ellipsis discovered through the analysis. In other words, four explicitated ellipsis and 32 transferred ellipsis were done by both translators. This means that transferred cases of ellipsis outweighed the explicitated ones by eight times. Therefore, it can be implied that the translators' inclination was towards leaving ellipsis untouched in the target version as the original one.

TABLE 2. Quantity of Conjunctions, Explicitated and, Non-explicit Conjunctions

\begin{tabular}{|c|c|c|c|c|}
\hline Text & Studied Words & $\begin{array}{c}\text { Quantity Of } \\
\text { Conjunctions Found }\end{array}$ & $\begin{array}{c}\text { Quantity Of } \\
\text { Explicitated } \\
\text { Conjunctions }\end{array}$ & $\begin{array}{l}\text { Quantity Of Non-Explicit } \\
\text { Conjunctions }\end{array}$ \\
\hline $\begin{array}{c}\text { The Glorious } \\
\text { Quran }\end{array}$ & 10660 & 1200 & 1100 & 100 \\
\hline
\end{tabular}

Table 2 maps out the statistics related to the number of conjunctions found in the source text and their translations. It is perceived that through the corpus of this study, 1200 cases of conjunctions were uncovered, among which the cases of explicitated conjunctions accounted almost 11 times more than the non-explicit conjunctions.

TABLE 3. Quantity of Substitutions, Explicitated and Transferred Substitutions

\begin{tabular}{ccccc}
\hline Text & Studies Words & $\begin{array}{c}\text { Quantity Of } \\
\text { Substitutions Found }\end{array}$ & $\begin{array}{c}\text { Quantity Of } \\
\text { Explicitated } \\
\text { Substitutions }\end{array}$ & $\begin{array}{c}\text { Quantity Of } \\
\text { Transferred } \\
\text { Substitutions }\end{array}$ \\
\hline The Glorious Quran & 10660 & 13 & 3 & 10 \\
\hline
\end{tabular}

Table 3 represents the number of substitutions, and their translations in the target text. It is observed that out of 13 substitutions found in the study of 10660 terms, 3 of them were explicitated and 10 of them transferred. In fact, the transferred ones accounted nearly three times more than explicitated ones. 


\section{CONCLUSIONS}

This study aims to discover clear-cut distinctions in the relationship between expertise and explicitation in Arabic-English translation of the Quran. Combining and going with BlumKulka's explicitation hypothesis and Halliday's notion of cohesion, it was claimed that the translated texts would be more explicit than their corresponding original texts and that texts translated by experienced translators would be more explicit. The three types of cohesive markers, as discussed by Halliday's notion of cohesion in English, were applied in the study. These were ellipsis, conjunction, as well as substitution. However, the findings turned out to be at odds with this hypothesis. They pointed to the fact that translators, be it experienced or inexperienced while avoiding the explicitation of ellipsis in addition to substitutions as employed in the target text, transferred most of the ellipsis and substitutions used in the source text in their intact shape; that is, it is sometimes necessary to do away with explicitation so as to achieve an easy path towards processing and unambiguous clarity of the message intended. To achieve an easily readable text, to discern the communicative preferences in the languages in question, and to decrease processing costs, the translators, throughout the translation product, avoided explicitating the ellipsis and substitutions used as such in the source text. This study brought out no clear relationship between expertise and explicitation in translation.

On the whole, it is safe to say that even though this study was rather small-scale and the evidence in all likelihood inadequate, the results suggested that there are considerable differences in the deliberate behavior of translators at different skill levels in dealing with the issue of explicitation, regardless of their experience or strategies. On account of various factors, as opposed to the professional translator, novice translators employ explicitation strategies more frequently and thus produce longer and more redundant texts. Translators who were professional, on the other hand, manipulate the translation length and explicitation more flexibly. All in all, what we tend to argue here is that the investigation of explicitation can go a long way towards painting a good picture of translators' expertise and the translation process. The insights from the present study suggest that compared to other cohesive markers in translated texts, conjunctions tend to be more explicit in Arabic-English translation. Also, last but not least, this study could not find any specific interaction and relationship between the level of expertise and explicitation in Arabic-English translation. Researchers are recommended to propose the practice of expertise and explicitation along with the quality assessment of the translations of the Quran verses based on the discoursal approaches as in House's to ascertain novel discoveries (Aidinlou, Dehghan, \& Khorsand, 2014; Khorsand \& Salmani, 2014a). This can be done particularly regarding the stories elaborated in more detail in the Quran. Interestingly, there have been a couple of poetic translations of the Quran generated into Persian, which can be the focus of the analysis either through the expertise and explicitation or plus quality assessment (Khorsand \& Salmani, 2014b). Moreover, ideology, the Quran translations and expertise can be investigated comaratively in several languages as the diverse discourses. This can be carried out with the attention to the pupose of the translations, for example considereing the translations produced specifically to children (Pym, 1996; Khorsand, \& Salmani, 2014c).

\section{ACKNOWLEDGMENTS}

We would like to acknowledge Dr. Bahloul Salmani's indispensable assistance and express our appreciation for all his support, particularly regarding the review of this paper and adding insightful comments. Further, we give our special gratitude to all our professors, predominantly Dr. Davud Kuhi and Dr. Bahram Behin, whose comments and views would be truly constructive. 


\section{REFERENCES}

Abdul-Ghafour, A. Q. K. M., Awal, N. M., Zainudin, I. S., \& Aladdin, A. (2019). The Interplay of Qur'ānic Synonymy and Polysemy with Special Reference to Al-asfār and Al-kutub (the Books) and their English Translations. 3L: Language, Linguistics, Literature ${ }^{\circledR}, 25(1)$.

Aidinlou, N. A., Dehghan, H. N., \& Khorsand, M. (2014). Ideology, change \& power in literature and society: A critical discourse analysis of literary translations. International Journal of Applied Linguistics and English Literature, 3(6), 260-271.

Amirdabbaghian, A. (2017). Translation of Power and Solidarity Pronouns in Qur'anic Rhetoric. Journal of Language and Translation, 7(3), 65-73.

Baker, M. (1992) In Other Words-A Coursebook on Translation. Routledge, London, and New York.

Baker, M. (1993). Corpus linguistics and translation studies: Implications and applications. In M. Baker, G. Francis \&E. Tognini-Bonelli (Eds.), Text and technology: In honor of John Sinclair (pp. 233-250). Philadelphia and Amsterdam: John Benjamins.

Baker, M. (1996). Corpus-based Translation Studies: The challenges that lie ahead. In H. Somers (Ed.), Terminology, LSP and Translation Studies in Language Engineering in Honour of Juan C.Sager (pp. 175-186). Amsterdam/Philadelphia: Benjamins.

Baker, M. (2000): "Towards a Methodology for Investigating the Style of a Literary Translator," Target 12(2): 241-66.

Baker, M. (2008). Routledge encyclopedia of translation studies. Routledge.

Baker, M., \& Maeve O. (2000). "Reporting that in Translated English: Evidence for Subconscious Processes of Explicitation?" Across Languages and Cultures 1(2): 141-58.

Blum-Kulka, Sh. (1986). Shifts of Cohesion and Coherence in Translation. In J. House and Sh. Blum-Kulka (eds.), Interlingual and Intercultural Communication. Discourse and cognition in translation and second language acquisition (pp. 17-35). Tübingen: Narr.

Crane, P. A. (2006). Texture in Text: A Discourse Analysis of a News Article Using Halliday and Hasan's Model of Cohesion. 名古屋外国語大学外国語学部紀要, 30, 131-156.

Dimitrova, B. E. (2005). Expertise and explicitation in the translation process (Vol. 64). John Benjamins Publishing Co.

Gutwinski, W. (1976). Cohesion in literary texts. The Hague: Mouton.

Hadidi, Y. (2016). Comments on Nonfinite Adverbial Patterns in English Prose Fiction: A Simple Model for Analysis and Use. Research in Applied Linguistics, 7(2), Fall 2016.

Halliday, M. A. K., \& Hasan, R. (1976). Cohesion in English (English Language).

Halliday, M. A. K., \& Matthiessen, C. M. I. M. (2004). An introduction to functional grammar (3rd ed.). London: Arnold.

Halliday, M.A.K. (1973). Explorations in the Functions of Language. London: Edward Arnold.

Irving, T. B. (1992). Qur'an: The First American Version. Amana Publications.

Khansary, M. A., (2009). The Bright Lights of Guidance. Qum.

Khorsand, M., \& Salmani, B., (2014a). Translation Quality Assessment: A Discoursal Approach in Theory and Practice. H. Translation Project Publishing.

Khorsand, M., \& Salmani, B., (2014b). Anthems as Propaganda: A Discoursal Translation Quality Assessment. International Journal of Language Learning and Applied Linguistics World (IJLLALW), 5(3), 222-237.

Khorsand, M., \& Salmani, B. (2014c). Manipulation of Original Ideology through Translation: A Discourse-Based Translation Quality Assessment of Speeches. International Journal of Applied Linguistics and English Literature (IJALEL), 3(5), 134-149.

Kienpointner, M. (2011). Figures of speech. In J. Zienkowski, J. Östman, \& J. Verschueren (Eds.), Discursive pragmatics (pp. 102-119). Amsterdam: John-Benjamins.

Klaudy, K. (1993). "On Explicitation Hypothesis," in K. Klaudy, J. Kohn. (eds.), Transferre necesse est... Current Issues of Translation Theory. In honour of György Radó, Szombathely, Daniel Berzsenyi College Printing Press, 69-77.

Klaudy, K. (1998). "Explicitation." In: Baker, M. (ed.), Encyclopaedia of Translation Studies, London, Routledge.

Klaudy, Kinga \& Károly, Krisztina. (2005). Implicitation in Translation: Empirical Evidence for Operational Asymmetry in Translation. Across Languages and Cultures - ACROSS LANG CULT. 6. 13-28. 10.1556/Acr.6.2005.1.2.

Laviosa-Braithwaite, S. (1998). 'Universals of translation', in Mona Baker (ed.) (1998) 'Routledge Encyclopedia of Translation Studies'. London \& New York: Routledge.

Malmkjær, K. (Ed.). (2017). The Routledge handbook of translation studies and linguistics. Routledge. 
Mir Aneesuddin (1992). A Simple Translation of The Holy Quran (with notes on Topics of Science). Islamic Academy of Sciences.

Mohaghegh, A., \& Pirnajmuddin, H. (2013). The trace of translators' ideology: A case study of English translations of the Qur'an. 3L: Language, Linguistics, Literature ${ }^{\circledR}, 19(1)$.

Munday, J. (2016). Introducing translation studies: Theories and applications. Routledge.

Nida, E. A. (1964). Toward a science of translating (pp. 59-69). Leiden: Brill.

Olohan, M. (2008). Leave it out! Using a Comparable Corpus to Investigate Aspects of Explicitation in Translation. Cadernos de Tradução, 1(9), 153-169.

Pápai, S. (2001). Strategyproof and Nonbossy multiple assignments. Journal of Public Economic Theory, 3(3), 257-271.

Pym, A. (1996). Ideologies of the expert in discourses on translator training. Problems and Trends in the Teaching of Interpreting and Translation. 139-149.

Pym, A. (2005). Explaining explicitation. New Trends in Translation Studies. In Honour of Kinga Klaudy. Budapest: Akadémia Kiadó, 29-34.

Ravelli, L. J. (1999). Renewal of connection: Integrating theory and practice in an understanding of grammatical metaphor. In A. Simon-Vandenbergen, M. Taverniers, \& L. J. Ravelli (Eds.), Grammatical metaphor: Views from systemic functional linguistics (pp. 37-64). Amsterdam: John Benjamins.

Séguinot, C. (1988). Pragmatics and the explicitation hypothesis. TTR: traduction, terminologie, rédaction, 1(2).

Tang, F., \& Li, D. (2017). A corpus-based investigation of explicitation patterns between professional and student interpreters in Chinese-English consecutive interpreting. The Interpreter and Translator Trainer, 11(4), 373-395.

Thompson, J. (2004). Introducing functional grammar. London: Arnold.

Vander, A. J., Longhi, J., \& Duchesne, J. C. (1998). A liquid line of descent of the jotunite (hypersthene monzodiorite) suite. Journal of Petrology, 39(3), 439-468.

Vinay, J. P., \& Darbelnet, J. (1995). Comparative stylistics of French and English: A methodology for translation (Vol. 11). John Benjamins Publishing. 